\title{
Assessment, Diagnosis and Prognosis of Bells Palsy: A Literature Review
}

\begin{abstract}
Facial (VII th cranial nerve) palsy is a condition that affects 1 in 5000 people worldwide. More recently it has appeared as one form of the neural manifestations of infection by the Human Immunodeficiency Virus. As such it is likely that this condition will feature more prominently in the caseload of physiotherapists. Therefore the purpose of this paper is to present to physiotherapists existing knowledge on the diagnosis, objective assessment and prognosis of facial palsy through a literature review. All available primary and secondary sources of literature were obtained through a search of Medline, Sabinet, PEDRO, the Cochrane library and a wide Google search. Objective ways of assessing Bells palsy and its recovery as used currently by the Belly Palsy Association and accepted by the American Academy of Otolaryngology and Head and Neck, are presented together with diagnosis and prognosis.
\end{abstract}

KEYWORDS : BELLS PALSY, PROGNOSIS, DIAGNOSIS, LITERATURE REVIEW.

\section{INTRODUCTION}

Bell's palsy is the sudden onset of weakness or paralysis of one side of the face due to inflammation of the facial nerve within the facial canal (Hurst 1998). Bell's palsy occurs most commonly between the ages of 15 to 60 years and has no gender preference, to date (Williams et al 1980). The Bell's palsy Association (2005) reported that approximately 1 case per 5000 population is likely to suffer from Bell's palsy.

\section{DIAGNOSIS}

Clinical diagnosis is made by a neurologist or ear, nose and throat specialist based on history and physical findings of the patient. The doctor may order blood tests, a Magnetic Resonance Image (MRI), a Computerised axial tomo-

\section{Correspondence to:}

Prof T. Puckree

Department of Physiotherapy

University of

Kwa Zulu Natal- Westville Campus

Private Bag X54001

Durban

4001

Tel: (032) 260-7977

Fax: (031) 260-8106

E-mail:puckree@ukzn.ac.za graph $(\mathrm{CT})$. The primary role of these tests in cases of suspected Bell's palsy is to exclude the possibility of other mass lesions and infections that can lead to facial nerve paralysis (Poolos 2001). Although the MRI or CT scan are considered diagnostic tools to rule out other causes, these tests are reserved when total paralysis persists due to the high costs. Anecdotal evidence suggests that this is especially the case in government hospitals throughout South Africa due to budgetary constraints. Therefore Bell's palsy is mainly diagnosed by exclusion of other conditions i.e. if the cause of facial paralysis is unknown the patient will be diagnosed with Bell's palsy (Weatherall et al 1996).

\section{Differential diagnosis}

The differential diagnosis for facial paralysis is broad and must include Ramsey Hunt Syndrome, traumatic lesions, upper motor neurone lesions, Melkersson-Rosenthal syndrome, metastatic neoplasms, sarcoidosis and Lyme disease (Hurst 1998). By far idiopathic facial paralysis/Bell's palsy which is a lower motor neuron lesion predominates, to account for about $80 \%$ of all cases of facial paralysis. The second most common cause of facial palsy is trauma (Poolos 2001). If there is history of injury (fractures of the temporal bone), this diagnosis may be confirmed by a high resolution CT scan. The facial nerve is susceptible to injury (primary or secondary swelling) as it passes through the meatus in the temporal bone

Ramsey Hunt syndrome also results in facial paralysis similar to that presented by Bell's palsy. Ramsey Hunt syndrome is caused by the varicella zoster virus and the incidence increases significantly after the age of 50 (Bradley et al 2004). There are patterns and symptoms that differentiate Ramsey Hunt syndrome from Bell's palsy. Firstly, the primary symptom of Ramsey Hunt syndrome is the appearance of painful blisters (Herpes Zoster vesicles) in and on the pinna of the ear, in the mouth or throat (Poolos 2001). These blisters may appear concurrently with the facial paralysis or 1.5 to 3 days after, and they can be expected to last from 2 to 5 weeks. Bell's palsy patients complain of acute pain in and behind the ear. Pain asso ciated with Ramsey Hunt syndrome is more severe and is felt inside the ear. While pain due to Bell's palsy fades within 1 to 2 weeks, pain with Ramsey Hunt syndrome can lasts for months (Williams et al 1980). Vertigo is more severe and lasts longer as a result of Ramsey Hunt syndrome. Ramsey Hunt 
syndrome can also affect the auditory nerve (8th cranial nerve) resulting in a hearing deficit. In some cases this hearing deficit may persist long after facial muscle function returns. Only about 50\% of Ramsey Hunt Syndrome patients regain normal function of facial muscles as opposed to $90 \%$ of patients with Bell's palsy (Poolos 2001).

Acute Otitus media can provide a source of direct bacterial invasion and inflammation along the facial nerve within the facial canal. Chronic otitus media may cause facial paralysis, which is usually secondary to cholesteatoma or from inflammation/osteitis compressing the facial nerve. Diagnosis is made with a high resolution CT scan. Approximately $5 \%$ of cases of facial palsy are caused by tumours, which usually elicit slow development of paresis. With tumours the best diagnostic tools include a CT scan or MRI (Hurst 1988).

Melkerson-Rosenthal Syndrome results in recurrent orofacial edema, recurrent facial palsy and lingua plicata/ fissured tongue (Poolos 2001). The distinguishing feature here is the persistent, recurrent, non-pitting edema. Other causes of facial palsy include sarcoidosis where diagnosis is confirmed by an elevated serum angiotensin-converting enzyme and Lyme disease where infection is caused by the tick-borne spirochete Borrelia burgdorferi (Bradley et al 2004).

With facial paralysis there exist several differences in symptoms between an upper motor neurone lesions as compared to a lower motor neurone lesion as in the case of Bell's palsy. Facial palsy due to an upper motor neurone lesion is usually part of a hemiplegia where the movements of the lower part of the face (specific muscles not confirmed by research) are usually more severely affected than those of the upper part (orbicularis oculi, frontalis and corrugator muscles) (Poolos 2001).

Immunocompromise caused by HIV infection allows for a greater incidence of viral infection and associated facial palsy. The single most common diagnosis given for HIV infected patients with seventh nerve paralysis is Bell's palsy (Poolos 2001).

Due to the similarity of causes of facial palsy it is imperative that clinical diagnosis is based on a thorough history, taking into account 3 important steps: identification of the affected site, underlying etiology (trauma, infectious, neoplastic) and clinical staging (e.g. using the House Brackmann facial nerve grading scale) (Poolos 2001). Bell's palsy remains a diagnosis of exclusion from other forms of facial palsy.

\section{ASSESSMENT TOOLS FOR PHYSIO- THERAPISTS}

Although there are several facial function reporting systems there is no globally accepted one. Therefore in 1984 the American Academy of Head and Neck Surgery adopted the HouseBrackmann Facial Nerve Grading Scale (House et al 1985). Other tools used for the evaluation of facial muscles include facial landmarks (Burres 1985), videotape where patients are asked to perform specific facial movements using an established protocol (Balliet 1989) or photography, which remains the most subjective. Videomicroscaling superimposes a computer-generated measuring scale over a video recorded image of facial movements. Distances moved are determined digitally. Wood et al (1994) examined variability in facial movements of normal subjects using video microscaling. They concluded that the average variability was relatively low but some subjects exhibited considerable variability, hence the authors questioned the validity of this evaluation method. Because physiotherapists need to quantify responses to therapy on a regular basis, the following tools will provide useful additions to their existing ones.

The House-Brackmann Facial Nerve Grading Scale is used to assess the severity of a patient's facial nerve recovery (House et al 1985). It holistically takes into account the overall facial paralysis by considering tone, symmetry, positions at rest, the motion of the forehead, eye and mouth and synkinesis. It has been widely and successfully used in previous studies (Sillman et al 1992, Targan et al 2000, Shrode 1993 and Stankovic 2002. In 1984 the American Academy of Otolaryngology - Head and Neck Surgery, Inc. adopted the HouseBrackmann Facial Nerve Grading Scale as their official facial nerve grading scale at the Fifth International
Symposium on the Facial nerve (House et al 1985).

Yen et al (2003) undertook a study to establish the significance of the HouseBrackmann Facial Nerve Grading Scale in the setting of differential function along the branches of the facial nerve i.e. a Regional House-Brackmann Facial Nerve Grading Scale. This regional scale was an evaluation of the forehead, eye, nose and mouth graded separately (4 grades) as compared to the traditional House-Brackmann Facial Nerve Grading System which took into account the overall facial muscle function and provides a single grade at the end of the assessment. Their study concluded that a single grade as furnished by the traditional House-Brackmann Facial Nerve Grading Scale did not always correlate with the best or worst function along these 4 facial regions in patients with variable facial weakness. Thus the regional scale (forehead, nose, eye and mouth) communicated more fully the actual facial function of each part of the face in more detail.

This instrument will help the clinical and research therapist quantify responses to therapy thereby ultimately providing some evidence for therapy. It does not require certification prior to use in any of these settings.

The Facial Disability Index is a disease specific, self-reporting system for the assessment of disabilities as a result of facial nerve paralysis. The Facial Disability Index consists of a physical functioning scale and a social functioning and well-being scale. In 1996, Van Swearing et al did a study to establish the reliability and validity of the Facial Disability Index. They concluded that the Facial Disability Index subscales produce reliable measurements, with construct validity for patientfocused disability of individuals with facial nerve disorders. The subscales of the Facial Disability Index provide reliable measurements of self-reporting of facial disabilities and have been used more frequently in recent studies (Beurskens et al 2003). The Facial Disability Index hollistically takes into account a patient's physical and social functional ability. It is a useful tool for the clinician especially because it is easy to use and not very time consuming. 


\section{Electrodiagnostic studies in facial paralysis}

The nerve excitability test (NET), the maximal stimulation test (MST) and the electroneurography (EnoG)/evoked electromyography (EEMG) are the most common electrodiagnostic tests used in acute Bell's palsy (May et al 1983). However these tests must be carried out 72 hours post onset of symptoms, once Wallerian degeneration has been completed. Wallerian degeneration is the process of degeneration of the neural fibres and occurs proximal to distally (Williams et al 1980).

The NET compares the current thresholds required to elicit minimal muscle contraction on the normal side of the face to those of the paralysed side. The MST is similar to the NET except that it uses maximum rather than minimal stimulation and responses are judged as a difference in facial movements. The EnoG/EEMG is considered the most accurate of all the prognostic/diagnostic tests as it does not rely on observer qualification and is used primarily in the evaluation of integrity of the facial nerve (Beck et al 1993). For the EnoG/EEMG there is a recording of the summation potential (compound action potential) for both the affected and unaffected sides. A comparison is made between the two sides and the degree of degeneration within the nerve is directly proportional to the amplitudes of the measured summation potentials (May et al 1983).

For a neuropraxia, all electrophysiological tests (NET, MST and EnoG/ EEMG) will be within the normal limits because Wallerian degeneration does not occur (Snyder-Mackler et al 1989). With axonotmesis and neurotmesis the electrical tests NET, MST and EnoG/ EEMG will demonstrate rapid or complete degeneration. With NET, MST and EnoG/EEMG the prognosis for recovery in neurotmesis/axonotmesis is less predictable. The nerve fibres may not be able to regenerate successfully and may result in a misdirection of nerve fibres resulting in synkinesis and incomplete facial function. The NET, MST and EnoG/EEMG can be use to distinguish if nerve fibres have undergone Wallerian degeneration but are unable to differentiate axonotmesis from neurotmesis (May et al 1983).
A difference of $3.5 \mathrm{~mA}$ is considered significant as it indicates severe degeneration and poor prognosis (May et al 1983). May et al (1983) also reported that in patients a response to the MST within the first 10 days had excellent recovery while over $85 \%$ of those who did not have a response to the MST for 10 days, did not fully recover. Sillman et al (1992) concluded from their study on the prognostic value of EnoG/EEMG that in acute paralysis when the amplitude of the affected side is less than $10 \%$ of the unaffected side, the prognosis is poor.

Electromyography (EMG) is used to detect muscle action potentials through the application of surface or needle electrodes (Oh 1998). Needle electrodes (pin-point contact) are more accurate than surface electrodes (due to crosstalk). However using needle electrodes is uncomfortable for patients and more cumbersome in everyday practise. When using EMG for facial nerve monitoring in the case of a neuropraxia of the facial nerve, voluntary motor action potentials cannot be conducted past the blockage thus the EMG is not a useful test for a neuropraxia (May et al 1983). The EMG will not demonstrate any voluntary motor units in the first 10 to 14 days. Only after this period will myogenic fibrillation potentials and indicators of axonal degeneration become evident (Oh 1988). EMG assessment occurs if motor units are observed with voluntary contraction. The EMG is used more commonly in long term evaluation of facial nerve paralysis and is useful as an adjunct to the MST and EnoG/EEMG (May et al 1983). The presence of myogenic fibrillation potentials and the absence of voluntary motor units denote complete degeneration while the coexistence of both defibrillation potentials and motor unit potentials indicates an incomplete lesion. The presence of polyphasic motor unit potentials signifies a regenerating nerve (Oh 1988).

\section{PROGNOSIS}

Bell's palsy progresses within several days to a maximum of 2 weeks. Approximately $75 \%$ of Bell's palsy sufferers recover within 2-3 months, $15 \%$ recovers within a year and about $10 \%$ never completely recover (Williams et al 1980, Farragher et al 1987). Recurrence can occur in 1 in 10 Bell's palsy sufferers, usually several years after the initial episode (Hurst 1992; Weatherall et al 1996).

While no single prognostic factor has been confirmed or refuted, research has suggested the following: degree of paresis and motor action potential value (Abraham-Inpijn et al 1987); serial minimal excitability of the facial nerve (Devi et al 1978); early intake of prednisolone (Shafshak et al 1994); the amplitude of evoked motor response obtained after 6 or more days of clinical paresis (Boongird and Vejjajiva 1978) and in children facial nerve latency was reported (Danselides et al 1992).

Clinical residuals are specific symptoms, which are more likely to occur and persist as a result of severe Bell's palsy. Severe and chronic Bell's palsy sufferers eventually use inappropriate muscles to compensate for the weakness. Often the disuse of the affected muscles persists as a habit even after nerve function has returned. This causes an unnatural pattern of movement which contributes to the defined list of clinical residuals as described by Targan et al (2000), Williams et al (1980), Hurst (1992), Farragher (2005) and Weatherall et al (1996). The longer one takes to recover, the greater the likelihood of clinical residuals occurrence and severity increases. HIV infected patients have the same prognosis for recovery as the general population (Murr et al 1991). However with immuno-compromised patients, concurrent opportunistic infections contraindicate the use of systemic steroids e.g. prednisone and this will affect prognosis.

\section{CONCLUSION}

The diagnosis and objective assessment of the response to intervention is critical in the quest to provide an objective base for physiotherapy practice. Facial nerve palsy is a condition that is likely to become more prevalent as the incidence of Human Immunodeficiency Virus and Auto Immume Disease increases. This paper tries to bring to the fore information from the literature that physiotherapists might find useful in the diagnosis and objective assessment of facial nerve palsy. 


\section{REFERENCES}

Abraham-Inpijn L, Oosting J, Hart AA 1987 Bells Palsy : factors affecting the prognosis in 200 patients with reference to hypertension and diabetes mellitus. Clinical Otolaryngology allied Sciences 12(5): 349-55

Balliet R 1989 Facial paralysis and other neuromuscular dysfunctions of the peripheral nervous system. Churchill Livingston New York pp: 175-213.

Beck DL, Benecke JE 1993 Electroneurography: Neurophysiological evaluation of the facial nerve. American Journal of Academic Audiology 4: 109-115

Beurskens CH, Heymans PG 2003 Positive effects of mime therapy on sequelae of facial paralysis: stiffness, lip mobility, and social and physical aspects of facial disability. Journal of Otology and Neuro-Otology 24(4): 677-681

Boongird P, Vejjajiva A 1978 Electrophysiologic findings and prognosis in Bells Palsy. Muscle Nerve 1(6): 461-6

Bradley WG, Daroff RB, Fenichel GM, Jankovic J 2004 Neurology in Clinical Practice. 2nd Edition Butterworth-Heinemann Philadelphia pps: 2115-2117, 2362, 2363, 2534, 2099-2101

Burres SA 1985 Facial Biomechanics: The standards of normal. Laryngoscope 95: 708-714

Danselides VG, Skevas AT, Panagopoulos K, Kastanioudakis 1992 Value of the facial nerve latency test in the prognosis of childhood Bells Palsy. Childs nervous system 8(3): 126-8

Devi S, Challenor Y, Duarte N, Lovelace RE 1978 Prognostic value of minimal excitability of facial nerve in Bells palsy. Journal of Neurology, neurosurgery Psychiatry 41(7): 649-52

Farragher D, Kidd GL, Tallis R 1987 Eutrophic Electrical stimulation for Bells Palsy. Clinical Rehabilitation 1: 265- 267

House JW, Brackmann DE 1985 Facial nerve grading system Otolaryngology - Head Neck Surgery 100: 146-147

Hurst WJ 1992 Medicine for the Practising Physician. 3rd Edition Butterworth-Heinmabb Stoneham, U.S.A, pgs: 1652, 1753-1755

May M, Blumenthal F, Klein SR 1983 Acute Bell's Palsy: prognostic value of evoked electromyography, maximal stimulation, and other electrical tests. American Journal of Otology 5(1): $1-7$

Murr AH, Bennecke JE 1991 Association of facial paralysis with HIV positivity. American Journal Otolaryngology 12: 450-451

Oh SJ 1988 Electromyography: Neuromuscular transmission studies. Williams and Wilkins Baltimore p: 56-63

Poolos NP 2001 Handbook of Differential Diagnosis in Neurology. ButterworthHeinemann Woburn, U.S.A. p: 4, 24, 25, 47, 39, 132. 7 .

Shafshak TS, Essa AY, Bakey FA 1994 The possible contributing factors for the success of steroid therapy in Bell's Palsy: a clinical and electrophysiological study. Journal of Laryngology and Otology 108(11): 940-3

Shrode LW 1993 Treatment of facial muscles affected by Bell's palsy with high-voltage electrical muscle stimulation. Journal of Manipulative Therapy 16(5): 347-352

Sillman JS, Niparko JK, Lee SS, Kileny PR 1992 Prognostic value of evoked and standard electromyography in acute facial paralysis. Otolaryngology - Head Neck Surgery 107: 377381

Snyder-Mackler L, Robinson AJ 1989 Clinical Electrophysiology. Williams and Wilkins Baltimore p:21-293

Stankovic M 2002 Surgery for facial nerve palsy. Balkan Journal of Otology and NeuroOtology 2(1): 14-17

Targan SR, Alon G, Kay SL 2000 Effects of long-term electrical stimulation on motor recovery and improvement of clinical residuals in patients with unresolved facial palsy. Otolaryngology - Head and Neck Surgery 122(2): 246-252

Van Swearing JM, Brach SJ 1996 The Facial disability Index: reliability and validity of a disability assessment instrument for disorders of the facial neuromuscular system. Physical Therapy 76: 1288-1300

Weatherall DJ, Ledingham GG, Warrel DA 1996 Oxford Textbook of Medicine. 3rd Edition Oxford University Press Inc. New York p: 3879, 3880

Williams LP, Warwick R 1980 Gray's Anatomy. 36th Edition Churchill Livingston Edinburgh pgs: 1070-1085; 529-536

Wood DA, Hughs GB, Secic M, Good TL 1994 Objective measurement of normal facial movement with video microscaling. The American Journal of Otology 15(1): 61-65 